\title{
Role of CT in Abdominal and Pelvic Trauma
}

\author{
Anagha R. Joshi • Atish L. Komwad • \\ Saurabh A. Joshi
}

Published online: 14 August 2014

(C) Springer Science+Business Media New York 2014

\begin{abstract}
With the trend toward non-operative management of blunt abdominal trauma, there is more responsibility on the diagnostic modalities for defining the injuries. CT scan is the investigation of choice due to its near $100 \%$ sensitivity with high negative predictive value. Plain- and contrast-enhanced images along with special modifications such as CT cystography, rectal contrast provide the necessary imaging information, which directs further patient management. The purpose of this article is to review the role of CT in abdominal and pelvic trauma.
\end{abstract}

Keywords CT $\cdot$ MDCT $\cdot$ Trauma $\cdot$ Abdomen $\cdot$ Pelvis

\section{Introduction}

Trauma can be defined as any bodily wound or shock produced by sudden physical injury, as from accident, injury or impact. In today's world, injury and trauma, which are often used interchangeably, represent a major health problem.

This article is part of Topical Collection on Abdominal CT Imaging

A. R. Joshi - S. A. Joshi

Department of Radiology, LTMMC \& LTMGH, Sion, Mumbai

400 022, Maharashtra, India

e-mail: anaghaj@gmail.com

S. A. Joshi

e-mail: saurabhanantjoshi@gmail.com

A. L. Komwad ( $\square)$

Department of Radiology, Government Medical College, Latur, India

e-mail: atishradio@gmail.com
Major trauma, also referred to as multiple trauma or polytrauma, is defined as potentially fatal injuries to more than one body region (head, chest, or abdomen and extremities). In patients with major trauma, the prompt and accurate diagnosis of injuries has the highest priority after admission.

Over the past few years, trauma has become one of the leading causes of morbidity and mortality of mankind. Globally one in ten deaths in both sexes are due to traumatic injuries, making it the sixth leading cause of death and the fifth leading cause of significant disability. In those between 15 and 45 years of age, trauma is the leading cause of death $[1 \bullet]$.

CT scan is a quick and widely available examination with virtually no contraindication for plain CT scan and altered renal function being only a relative contraindication for contrast-enhanced CT scan.

With the advent of multislice CT scanner, scan time is significantly reduced. Thin slices enable sharp images and excellent multiplanar reconstruction. Maximum intensity projection (MIP), minimum intensity projection (MinIP), surface-shaded display (SSD), volume-rendered technique (VRT) also aid in the diagnosis and are better for the roadmap for the understanding of the surgeon.

In abdomino-pelvic trauma; more than $50 \%$ of splenic injury, $80 \%$ of liver injury and virtually all renal injuries are managed non-operatively, because patients have been proved to have better outcomes in the long term related to visceral salvage $[2,3]$.

CT scan is the investigation of choice for defining the injuries with its role not only limited for initial assessment, but also being equally useful for follow-up of conservative management as well as post-operative patients.

Detection of retroperitoneal injuries (duodenum, pancreas, vascular, renal, and adrenal) is very important as these sites are difficult to be evaluated by ultrasonography. 
CT scan is also routinely used for penetrating abdominal injuries for having the detailed evaluation of associated injuries. These cases initially only went to operation tables.

Evaluations of lower chest sections and hence, lower bony thorax, pericardium, heart, lung parenchyma are done in one setting.

Injury to both visceral and musculoskeletal components of pelvis is quite common in cases of polytrauma, especially vehicular trauma.

Due to its serious immediate and late complications, pelvic trauma needs to be diagnosed as early as possible with maximum accuracy and minimal patient discomfort.

CT scanning, especially with tailor-made modifications such as CT Rectal contrast, CT cystography, CT urethrography combined with isotropic resolution made possible by present day MDCT scanners has potential to become the one stop shop for pelvis injuries.

Exquisite bony details given by CT are helpful for planning the orthopedic repair and in cases of spinal trauma to rule out neurological injuries.

\section{Protocol}

Protocol of a CT scan of a case of trauma has to be standardized. In our institution we follow a baseline protocol. Some points need to be highlighted.

- Oral contrast Previously with single-slice CT scan oral contrast was used in every patient. But with MDCT this is unnecessary as well as sometimes troublesome hampering the diagnostic ability. So the current consensus is not to use oral contrast in acute setting and in cases of diagnostic dilemma regarding bowel injury, use it for the subsequent CT scan after the patient becomes stable and acute event is managed.

- Serum Creatinine should be checked in all patients as trauma to kidney may derange renal function and iodinated contrast must be used cautiously in such cases.

- Adequate hydration pre- and post-procedure along with $\mathrm{N}$-Acetyl Cysteine should be advised for deranged renal function, in whom CT scanning is mandatory.

- Plain scan covering from lower thorax up to mid-thigh should be taken and sentinel clot sought for.

- Arterial and venous phase scans are taken with bolus tracking after administration of approx. $1.5 \mathrm{ml} / \mathrm{kg}$ of non-ionic contrast medium @ $3 \mathrm{ml} / \mathrm{s}$ at 15 and 45 s after the bolus tracking threshold (usually $100 \mathrm{HU}$ in lower thoracic aorta) is achieved.

- Delayed scan is taken at the end of 7-10 min after contrast injection.
- Rectal contrast studies are done to rule out penetrating or blunt bowel injuries after suspecting the same on routine scans.

- CT cystography is mandatory in every case of pelvic fracture to rule out bladder injury.

- CT urethrography can be done with dynamic urethral contrast injection in suspected urethral injuries.

- Lower chest sections can reveal some abnormalities such as lung contusions or ARDS like picture on plain images. In such cases, lung coverage should be considered in subsequent contrast-enhanced scans.

- Injuries to structures traversing multiple compartments such as vertebral fractures, oraortic injuries are better assessed in MPR images.

- Hence MIP, MPR, VRT, SSD etc., techniques should be used whenever necessary.

- Lung and bone window reconstructions and their documentations are necessary in relevant cases.

Tailoring your examination for every case of trauma individually is the most useful practice (Fig. 1).

\section{Peritoneal Spaces}

Sentinel clot search is of major importance in the plain scan (Table 1).

Active bleeding spot will have a sentinel clot. Proper soft tissue window with high index of suspicion to look at the specific and typical sites is necessary. In the ambulatory patients of the trauma, pelvis becomes the most dependent site for collection of hemoperitoneum [4]. Rectovesical pouch, paravesical fossae, and paracolic gutter show fluid accumulation progressively. In cases of severe hemoperitoneum as the area of highest density is usually the site of origin of blood, it should be observed carefully in the later scanning.

Supramesocolic spaces show hemoperitoneum in cases of upper solid organ injuries. The peritoneal boundaries are not respected in cases of severe hemoperitoneum and frequently fluid collects in paracolic gutters and pelvis.

Similarly, pneumoperitoneum should be looked for in the plain scan itself to rule out potential full thickness bowel injury, provided there is no evidence of penetrating trauma.

Pitfalls of pneumoperitoneum detection are air introduced through Foleys catheter in patients with intraperitoneal bladder rupture, foci of air from pneumothorax descending in the peritoneum, and diagnostic peritoneal lavage $[5,6]$.

Severe hemoperitoneum puts the patient at risk for hypotension and shock. Though this is primarily a clinical diagnosis, Collapse of IVC, small caliber of aorta, 

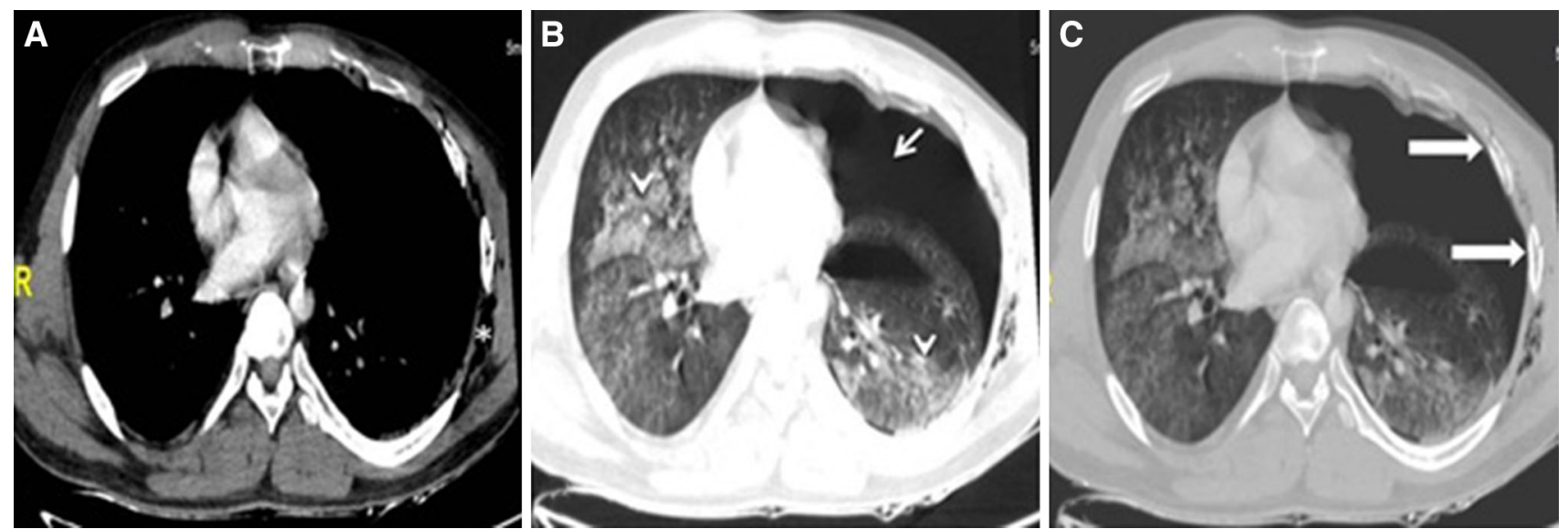

Fig. 1 Lower chest section in case of road traffic accident of a 26 year old male with soft tissue, lung and bone windowing. a Mild subcutaneous emphysema is seen adjacent to the left lower ribs (asterisk). b Severe left sided pneumothorax (arrow) with collapse of

persistent nephrogram without excretion, increased enhancement of the adrenal glands, and features of shock bowel are seen on CT scan and should be sought for with high degree of suspicion.

Attenuation values of various forms of ascites in trauma are explained in Table $2[4,7]$.

\section{Spleen}

Spleen is the most commonly injured organ in blunt abdominal trauma [8]. Left lower rib fracture with the left lung and areas of pulmonary edema are seen in bilateral lower lobes (arrowhead). c Linear mildly displaced fractures of the left lower ribs are seen (solid arrows)

hypotension should prompt the search for a splenic trauma. Findings of high vascularity along with splenic artery and veins being tortuous and significantly large in size make splenic injury patients vulnerable for hypotension. Vascular pedicle should be carefully evaluated for sentinel clot and in post contrast phases. Subcapsular splenic hematomas, missed at USG or rarely at CT, may bleed fatally even $48 \mathrm{~h}$ after initial trauma. This is the lucid interval of splenic trauma.

Post-splenectomy patients need to be put on long-term antibiotics and are prone for many threatening infections. In view of these facts, over-enthusiastic reporting forcing

Table 1 Scanning parameters used in CT abdomen for trauma

\begin{tabular}{|c|c|c|c|c|}
\hline \multirow[t]{2}{*}{ Phase } & \multicolumn{4}{|l|}{ Parameter } \\
\hline & Plain & Arterial & Venous & Delayed \\
\hline $\begin{array}{l}\text { Time after bolus } \\
\text { tracking threshold }\end{array}$ & Pre-contrast & $15 \mathrm{~s}$ & $45 \mathrm{~s}$ & $8 \mathrm{~min}$ \\
\hline Coverage & $\begin{array}{l}\text { Dome of diaphragm to lower } \\
\text { border of symphysis pubis }\end{array}$ & $\begin{array}{l}\text { Dome of diaphragm to lower } \\
\text { border of symphysis pubis }\end{array}$ & $\begin{array}{l}\text { Dome of diaphragm to scrotum (males) } \\
\text { or perineum (females) }\end{array}$ & $\begin{array}{l}\text { Kidneys, ureter, } \\
\text { urinary bladder }\end{array}$ \\
\hline $\begin{array}{l}\text { Thickness and } \\
\text { increment }\end{array}$ & $3 \mathrm{~mm}, 1.5 \mathrm{~mm}$ & $3 \mathrm{~mm}, 1.5 \mathrm{~mm}$ & $3 \mathrm{~mm}, 1.5 \mathrm{~mm}$ & $3 \mathrm{~mm}, 1.5 \mathrm{~mm}$ \\
\hline Collimation & $64 \times 0.625$ & $64 \times 0.625$ & $64 \times 0.625$ & $64 \times 0.625$ \\
\hline Pitch & 1.172 & 1.172 & 1.172 & 1.172 \\
\hline Filter & Smooth (A) & Smooth (A) & Smooth (A) & Smooth (A) \\
\hline Enhancement & 0 & 0 & 0 & 0 \\
\hline Window centre & 60 & 60 & 60 & 60 \\
\hline Width & 360 & 360 & 360 & 360 \\
\hline Centre $\mathrm{X}$ & 0 & 0 & 0 & 0 \\
\hline $\mathrm{Y}$ & 0 & 0 & 0 & 0 \\
\hline Matrix & 512 & 512 & 512 & 512 \\
\hline \multicolumn{5}{|l|}{ Reconstruction: } \\
\hline Thickness (mm) & 2 & 1 & 2 & 2 \\
\hline Increment (mm) & 1 & 0.5 & 1 & 1 \\
\hline
\end{tabular}


Table 2 Attenuation values of ascites

\begin{tabular}{ll}
\hline Ascites type & Attenuation (HU) \\
\hline Free fluid (simple ascites or urine) & $0-15$ \\
Free blood (without clot) & $20-40$ \\
Clotted blood & $40-70$ \\
Active bleeding & Within the range of 10 HU \\
& of adjacent major vessel \\
\hline
\end{tabular}

Table 3 Grades of splenic injuries [9••]

\begin{tabular}{|c|c|c|}
\hline Grade & Type & Features \\
\hline \multirow[t]{2}{*}{ I } & Hematoma & Subcapsular $<10 \%$ surface area \\
\hline & Laceration & Capsular tear $<1 \mathrm{~cm}$ parenchymal depth \\
\hline \multirow[t]{2}{*}{ II } & Hematoma & $\begin{array}{l}\text { Subcapsular, } 10-50 \% \text { surface area or }<5 \mathrm{~cm} \text { in } \\
\text { diameter }\end{array}$ \\
\hline & Laceration & $\begin{array}{l}\text { Capsular tear, } 1-3 \mathrm{~cm} \text { parenchymal depth that } \\
\text { does not involve a trabecular vessel }\end{array}$ \\
\hline \multirow[t]{2}{*}{ III } & Hematoma & $\begin{array}{l}\text { Subcapsular, }>50 \% \text { surface area or expanding; } \\
\text { ruptured subcapsular or parenchymal } \\
\text { hematoma; intraparenchymal hematoma } \\
>5 \mathrm{~cm} \text { or expanding }\end{array}$ \\
\hline & Laceration & $\begin{array}{l}>3 \mathrm{~cm} \text { parenchymal depth or involving } \\
\text { trabecular vessels }\end{array}$ \\
\hline IV & Laceration & $\begin{array}{l}\text { Laceration involving segmental or hilar vessels } \\
\text { producing major devascularisation }(>25 \% \text { of } \\
\text { spleen) }\end{array}$ \\
\hline \multirow[t]{2}{*}{$\mathrm{V}$} & Laceration & Shattered spleen \\
\hline & Vascular & Splenic devascularisation \\
\hline
\end{tabular}

surgeon for splenectomy, as well as underreporting of splenic trauma needs to be avoided.

Patterns of splenic injury are contusion, laceration, subcapsular hematoma, intrasplenic hematoma, splenic infarction, and devascularisation of spleen (Table 3; Figs. 2, 3).

\section{Liver}

The liver is next in the list after spleen to get injured in blunt abdominal trauma. MDCT is the investigation of choice for the evaluation of hemodynamically stable hepatic trauma patients $[10,11]$.

The range of imaging findings is wide and includes hematoma, contusion, laceration, active extravasation, and vascular injury. A contusion appears as an ill-defined area of non-enhancing hypodensity. Lacerations are usually linear or branching. The laceration of the bare area of the liver needs special attention as being a retroperitoneal structure; the hematoma is not seen in the Morrison's pouch. Instead, the hematoma is seen in the right anterior pararenal space. Lacerations in the bare area of the liver are frequently associated with right renal and adrenal injuries $[12 \bullet, 13]$. Hepatic lacerations extending to the vascular structures are important as IVC, and hepatic vein injuries are potentially fatal.

Active extravasation appears as an area of persistently high density on arterial phase, nearly the same as adjacent major vessel. This area increases in size in the venous and excretory phase and remains high density.

Arterio-portal fistulae and AV malformations are easily identified with thin slice MDCT (Table 4; Figs. 4, 5).

\section{Pancreas}

Pancreatic injury is mostly seen in blunt abdominal trauma and is rarely an isolated injury. Thin young adults or children are especially susceptible for pancreatic injury.

Usually the mechanism is large blow or kick to the abdomen or bicycle handle injury in a thin child. Lack of retroperitoneal fat cushion predisposes these patients to pancreatic injury. Imaging findings are varied ranging from
Fig. 2 Splenic injuries. Two different patients with splenic lacerations are depicted (a, b) (arrows). Observe the moderate perisplenic hematoma in the $\mathbf{b}$ (arrowheads)
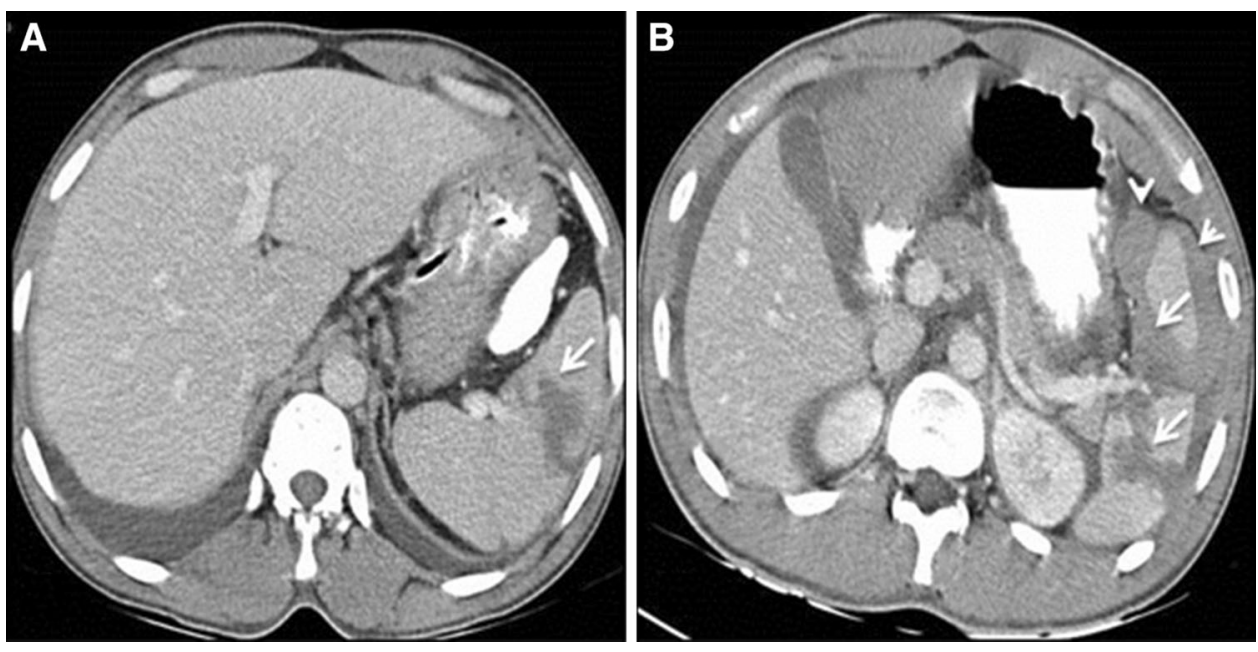
Fig. 3 Splenic injuries. a Plain and $\mathbf{b}$ venous phase of same patient of blunt abdominal trauma. A well demarcated area of non-enhancement in the upper pole of the spleen in posterior part s/o devascularization
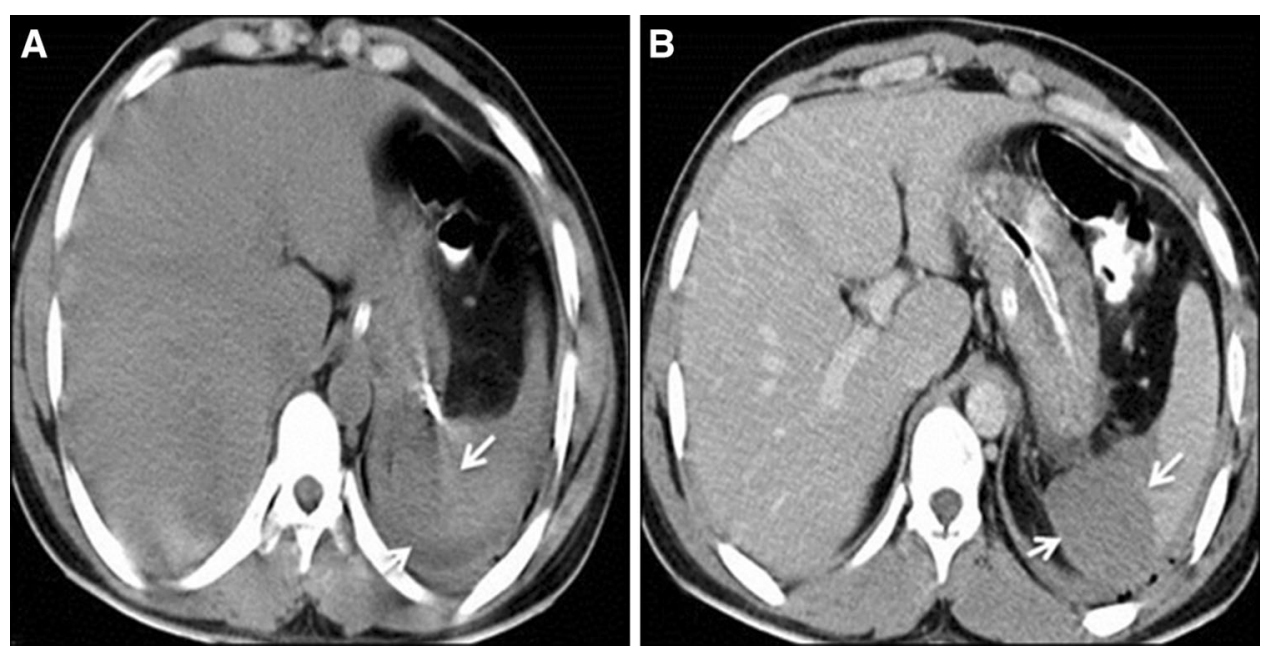

Table 4 Grades of liver injuries [9••]

\begin{tabular}{|c|c|c|}
\hline Grade & Type & Features \\
\hline \multirow[t]{2}{*}{ I } & Hematoma & Subcapsular $<10 \%$ surface area \\
\hline & Laceration & Capsular tear $<1 \mathrm{~cm}$ parenchymal depth \\
\hline \multirow[t]{2}{*}{ II } & Hematoma & $\begin{array}{l}\text { Subcapsular, } 10-50 \% \text { surface area or }<10 \mathrm{~cm} \\
\text { in diameter }\end{array}$ \\
\hline & Laceration & $\begin{array}{l}\text { Capsular tear, } 1-3 \mathrm{~cm} \text { parenchymal depth, } \\
<10 \mathrm{~cm} \text { in length }\end{array}$ \\
\hline \multirow[t]{2}{*}{ III } & Hematoma & $\begin{array}{l}\text { Subcapsular, }>50 \% \text { surface area or expanding } \\
\text { ruptured subcapsular or parecymal } \\
\text { hematoma; intraparenchymal hematoma } \\
>10 \mathrm{~cm} \text { or expanding }\end{array}$ \\
\hline & Laceration & $>3 \mathrm{~cm}$ parenchymal depth \\
\hline IV & Laceration & $\begin{array}{l}\text { Parenchymal disruption involving } 25-75 \% \text { of } \\
\text { hepatic lobe or } 1-3 \text { Couinaud's segments }\end{array}$ \\
\hline \multirow[t]{2}{*}{$\mathrm{V}$} & Laceration & $\begin{array}{l}\text { Parenchymal disruption involving }>75 \% \text { of } \\
\text { hepatic lobe or }>3 \text { Couinaud's segments } \\
\text { within a single lobe }\end{array}$ \\
\hline & Vascular & $\begin{array}{l}\text { Juxtahepatic venous injuries; i.e. retrohepatic } \\
\text { vena cava/central major hepatic veins }\end{array}$ \\
\hline VI & Vascular & Hepatic avulsion \\
\hline
\end{tabular}

only focal thickening or swelling of the gland to the extent of fracture of pancreas. Retroperitoneal fluid, hemorrhage, and thickening of anterior Gerota's fascia are the usual associated findings. Post-traumatic pseudocyst formation is common, and probably the most common cause of pancreatic pseudocyst formation in children is trauma.

Evaluation of pancreatic duct with MinIP technique is mandatory as the communication of the pseudocyst with the pancreatic duct makes it potentially intractable and recurrent. Routine images are less sensitive for pancreatic duct evaluation (Fig. 6).

Streak artefacts caused by the nasogastric tube or high density oral contrast in the stomach might hinder the pancreatic lesions associated with trauma.
Bowel, Omentum, and Mesentery

Small bowel injuries are uncommon isolated cases. Jejunum (ligament of Treitz) is the most common site of injury, followed by ileum, colon, rectum, duodenum, and stomach. The injuries can be grouped under full thickness or partial thickness tears. The typical fluid collection in the Morrison's pouch and paracolic gutters is not observed in bowel injury. Instead, thin pockets of fluid are seen in the interloop region in the mesentery. In cases of mild hemoperitoneum without evidence of solid organ injury, the radiologist must be alert for occult bowel injury.

Mild fluid with foci of pneumoperitoneum increases the probability of bowel injury. Oral or rectal contrast extravasation adjacent to the bowel loop has high probability of full thickness bowel injury [8, 14, 15].

Focus of mesenteric fat stranding and thickening in an unstable patient needs follow-up CT evaluation after 6-8 h for the change in size of the mesenteric lesion as this can be the only sign of ongoing mesenteric hematoma [14, 16, 17] (Fig. 7).

\section{Kidneys and Ureters}

Blunt trauma is more commonly associated with renal injury than the penetrating trauma [18]. Hematuria, gross or microscopic, is associated with majority of renal trauma cases. However, its absence does not rule out renal injury. Few cases of renal artery thrombosis and uretero-pelvic junction injuries may not present with hematuria and these findings need to be sought specifically in relevant clinical settings.

Ureteropelvic junction is the most common site for the ureteric injury. Compression against the transverse processes of lumbar vertebrae causes ureteric injury. Range of 
Fig. 4 Liver injuries. a Active extravasation in a laceration of the liver (arrow). b Hepatic laceration extending to hepatic veins and IVC (arrowheads) (These patients have high chances of mortality.)
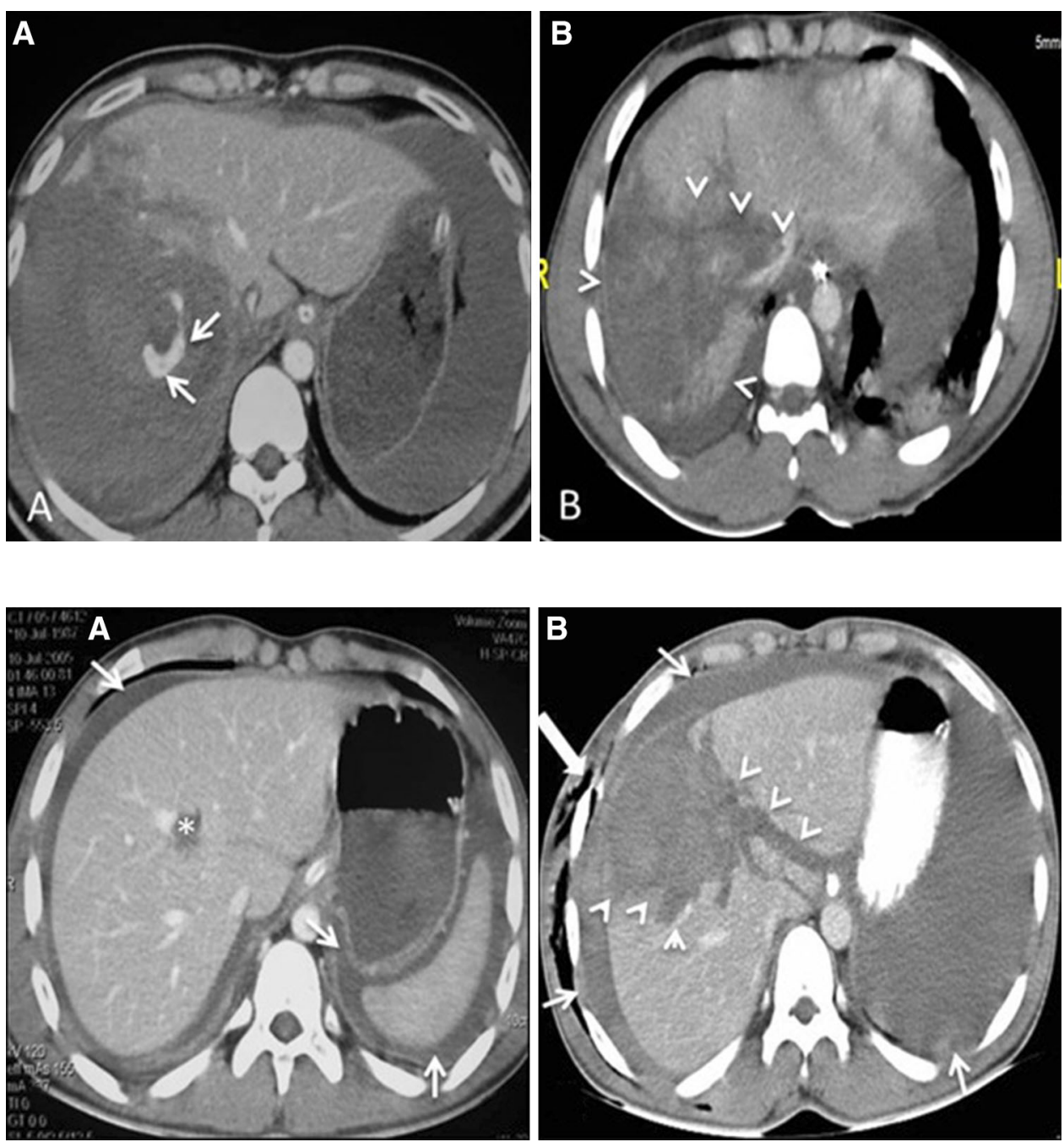

Fig. 5 Liver injuries. a Hepatic contusion (asterisk) and moderate hemoperitoneum (arrows). b Another patient hepatic laceration (arrowheads) through full thickness of liver with hemoperitoneum (arrows), right lower rib fracture and adjacent subcutaneous emphysema (solid arrows)

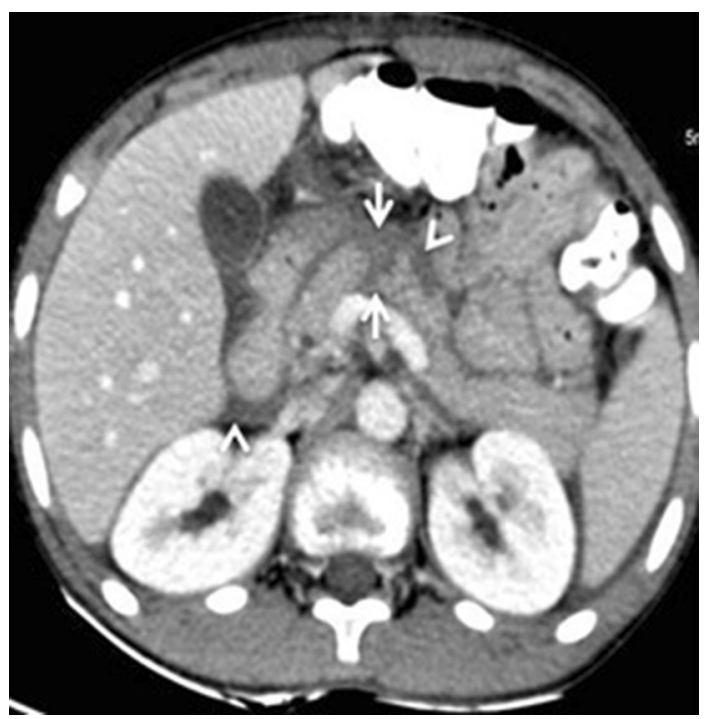

Fig. 6 Pancreatic injury. Pancreatic fracture through the body of pancreas (arrows) with moderate retroperitoneal collection (arrowheads)

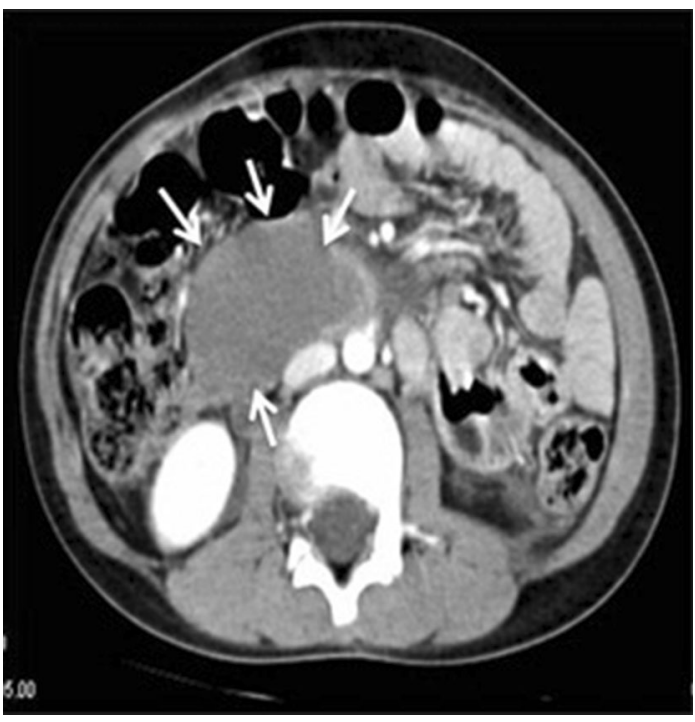

Fig. 7 Bowel injury. Duodenal hematoma. Axial sections reveal hypodense non-enhancing hemotoma involving 2nd-3rd part of duodenum (arrows) 
Table 5 Grades of renal injuries [9••]

\begin{tabular}{|c|c|c|}
\hline Grade & Type & Features \\
\hline \multirow[t]{2}{*}{ I } & Contusion & \\
\hline & Hematoma & $\begin{array}{l}\text { Subcapsular, non-expanding } \\
\text { (without laceration) }\end{array}$ \\
\hline \multirow[t]{2}{*}{ II } & Hematoma & $\begin{array}{l}\text { Non-expanding peri-renal, confinec } \\
\text { to renal retroperitoneum }\end{array}$ \\
\hline & Laceration & $\begin{array}{l}<1 \mathrm{~cm} \text { parenchymal depth without } \\
\text { urinary extravasation }\end{array}$ \\
\hline III & Lacertion & $\begin{array}{l}>1 \mathrm{~cm} \text { parenchymal depth without } \\
\text { urinary extravasation }\end{array}$ \\
\hline \multirow[t]{2}{*}{ IV } & Laceration & $\begin{array}{l}\text { Parenchymal laceration involving } \\
\text { the collecting system }\end{array}$ \\
\hline & Vascular & $\begin{array}{l}\text { Main renal artery or vein injury } \\
\text { with contained hemorrhage }\end{array}$ \\
\hline \multirow[t]{2}{*}{ V } & Laceration & Shattered kidney \\
\hline & Vascular & Renal devascularization \\
\hline
\end{tabular}

injuries includes contusion, partial tear, or complete disruption. Gynecological surgeries are important causes of iatrogenic ureteric injuries in females (Table 5; Figs. 8, 9, $10,11)$.

\section{Urinary Bladder}

Urinary bladder is frequently injured in cases of pelvic trauma, major mechanisms of injury being blunt trauma or penetrating trauma by fracture fragments.

The type and extent of bladder injury depends not only on the external mechanism of injury but also on the intrinsic state of the bladder at the time of injury, that is, whether the bladder was collapse (empty) or distended (full) at the instance of injury [19].

Diagnosis of bladder injury on MDCT can be challenging if the bladder is not well distended at the time of
Fig. 8 Renal injuries. a Grade 1 contusion (arrows). b Grade 2 laceration $<1 \mathrm{~cm}$ (arrowheads) without PCS extension
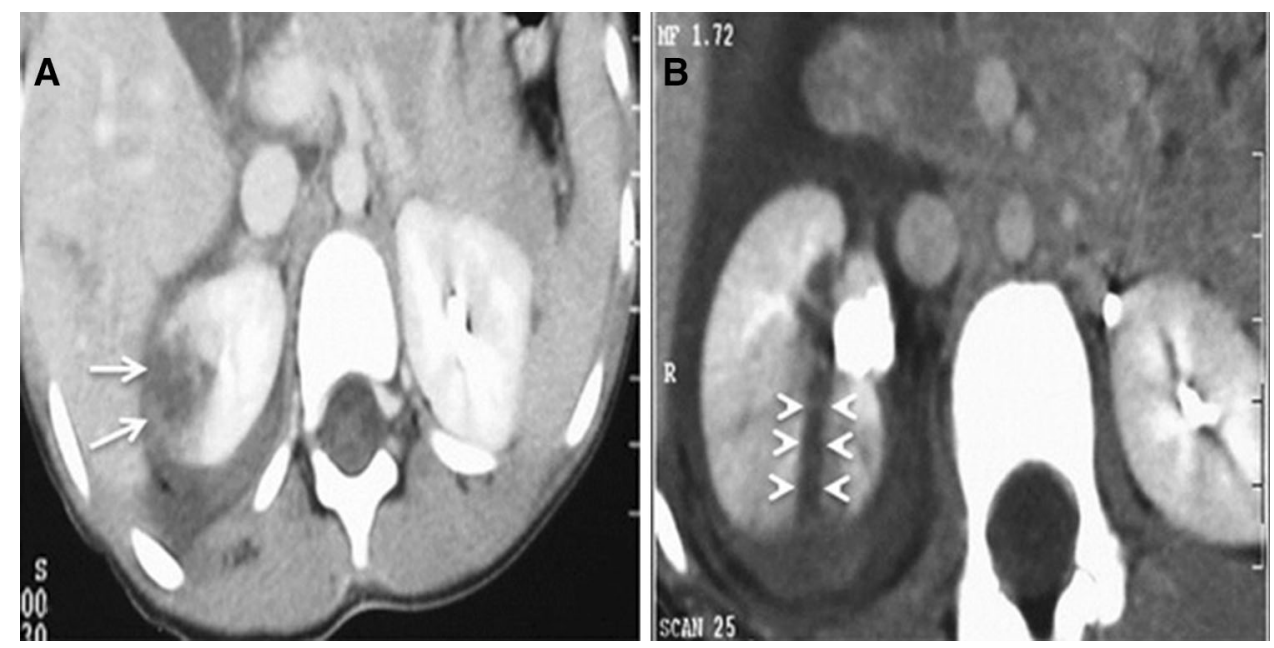

Fig. 9 Renal injuries. a Grade 3 laceration $>1 \mathrm{~cm}$ without urinary extravasation (arrows). b Grade 4 laceration with urinary extravasation (arrowheads)
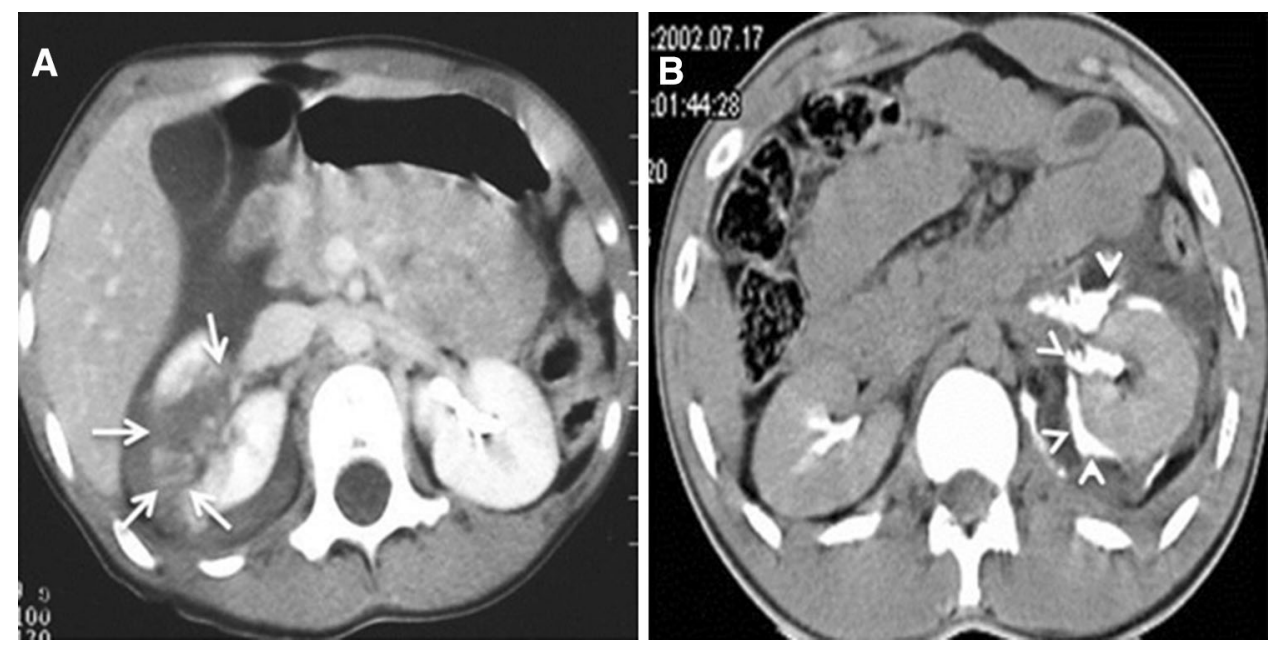
Fig. 10 Renal injuries. Plain (a), arterial (b), venous (c) and MIP (d) images of a patient. Left kidney shows no nephrogram and sudden cut off of the left renal artery is seen due to thrombosis (asterisk). Also associated splenic laceration (arrows) and pneumoperitoneum (arrowheads) is seen
Fig. 11 Ureteric injuries. Ureteric rupture with contrast opacified urinary extravasation (a, b) (arrows)
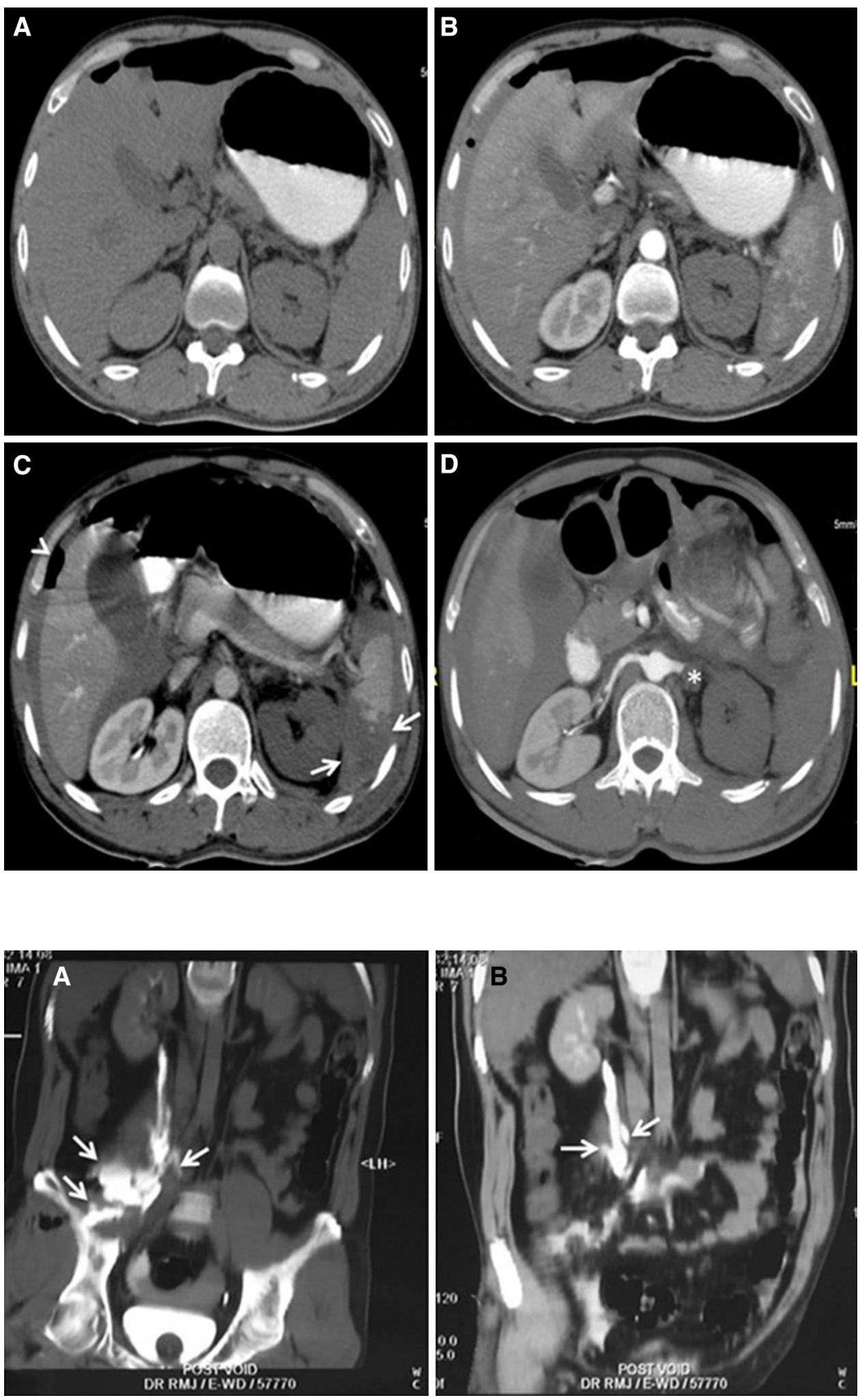

study [20]. As majority of the polytrauma patients are catheterized, either by transurethral or suprapubic route on admission in our institute, the bladder is empty when the patient comes for a CT scan.
Decision of performing a CT cystography is taken on the basis of clinical and radiological findings. Presence of pelvic fractures on prior radiographs or plain pre-contrast $\mathrm{CT}$ is the main determinant. However, even in absence of 


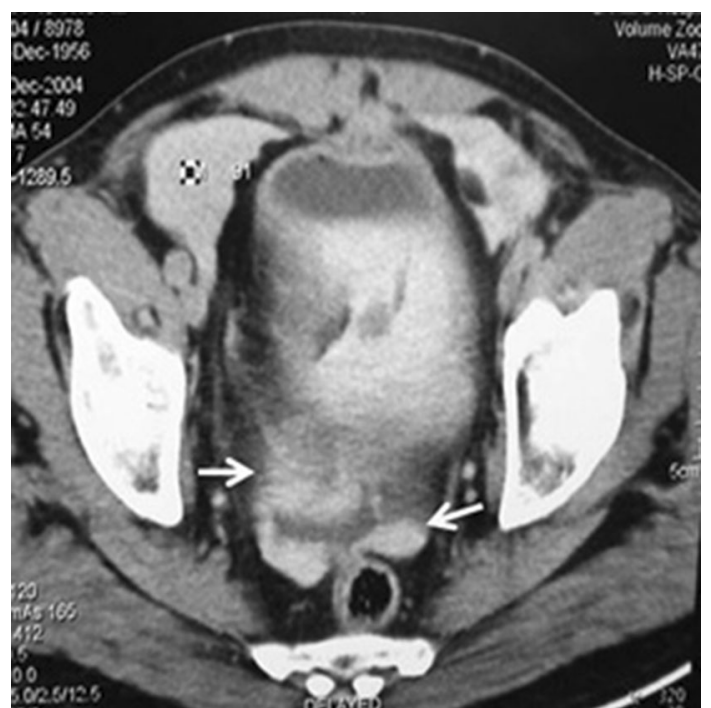

Fig. 12 Bladder injury. Extraperitoneal bladder rupture. Active leak of contrast from urinary bladder is seen (arrows) in extraperitoneal space these if clinical suspicion of bladder injury is present on the basis of findings such as passage of blood-tinged urine, elevated prostate on PR examination etc., CT cystography is performed.

The filling of bladder can be achieved either by ante grade or retrograde approach. The bladder catheter is clamped before the beginning of study and delayed scans taken at 8-10 min. In patients with preserved renal function, urinary bladder will be adequately distended with the opacified contrast. In cases with inadequate filling at this stage due to suboptimal renal function or other causes, instillation of 2-3\% diluted non-ionic contrast is done through the catheter and CT cystography performed from lumbar region to mid thighs. The extent of the scan is longer than the coverage needed for bladder to detect any extravasation of contrast material.

In some cases, even with a collapsed bladder, free contrast is noted intra or extra-peritoneal location on delayed scan. In such cases, exact localization of tear may warrant a formal cystography.
Fig. 13 Bladder injury. Extraperitoneal bladder rupture. Delayed phase axial CT images showing extravasation (arrows) of the urinary bladder contrast in the extraperitoneal location (a), pelvic musculature and intermuscular plane (b, c) (curved arrows) and in the perineal region (b). The contrast is seen tracking in the scrotal sac (d) (curved arrow)
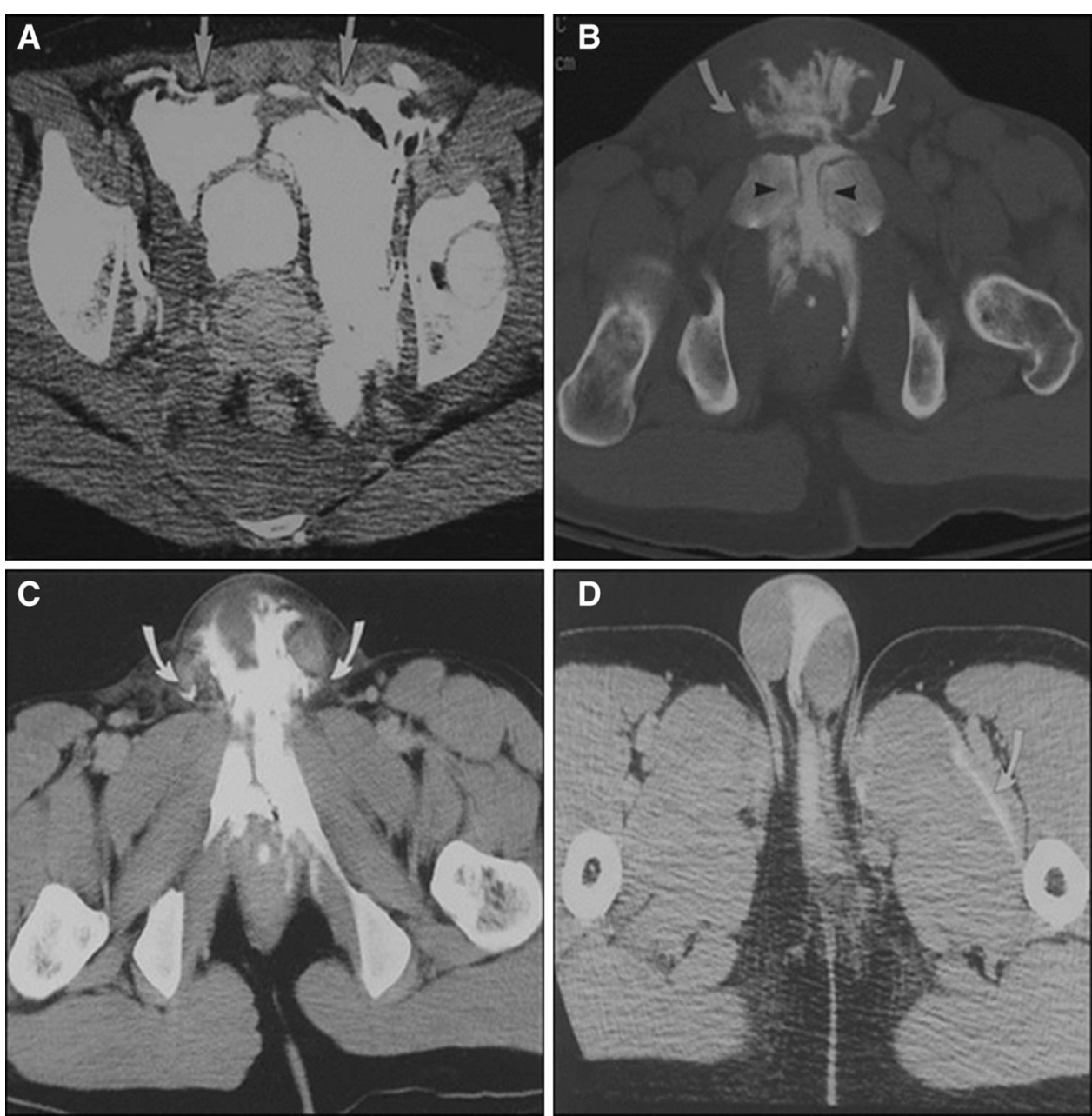

a Coronal and b sagittal reformat of CT pelvis showing moderate thickening (arrows) in the supero-lateral perivesical region without obvious contrast leak s/o perivesical mesenteric importance of CT Cystography in pelvic trauma to rule out bladder rupture
Fig. 14 Bladder injury. hematoma. This underlines the
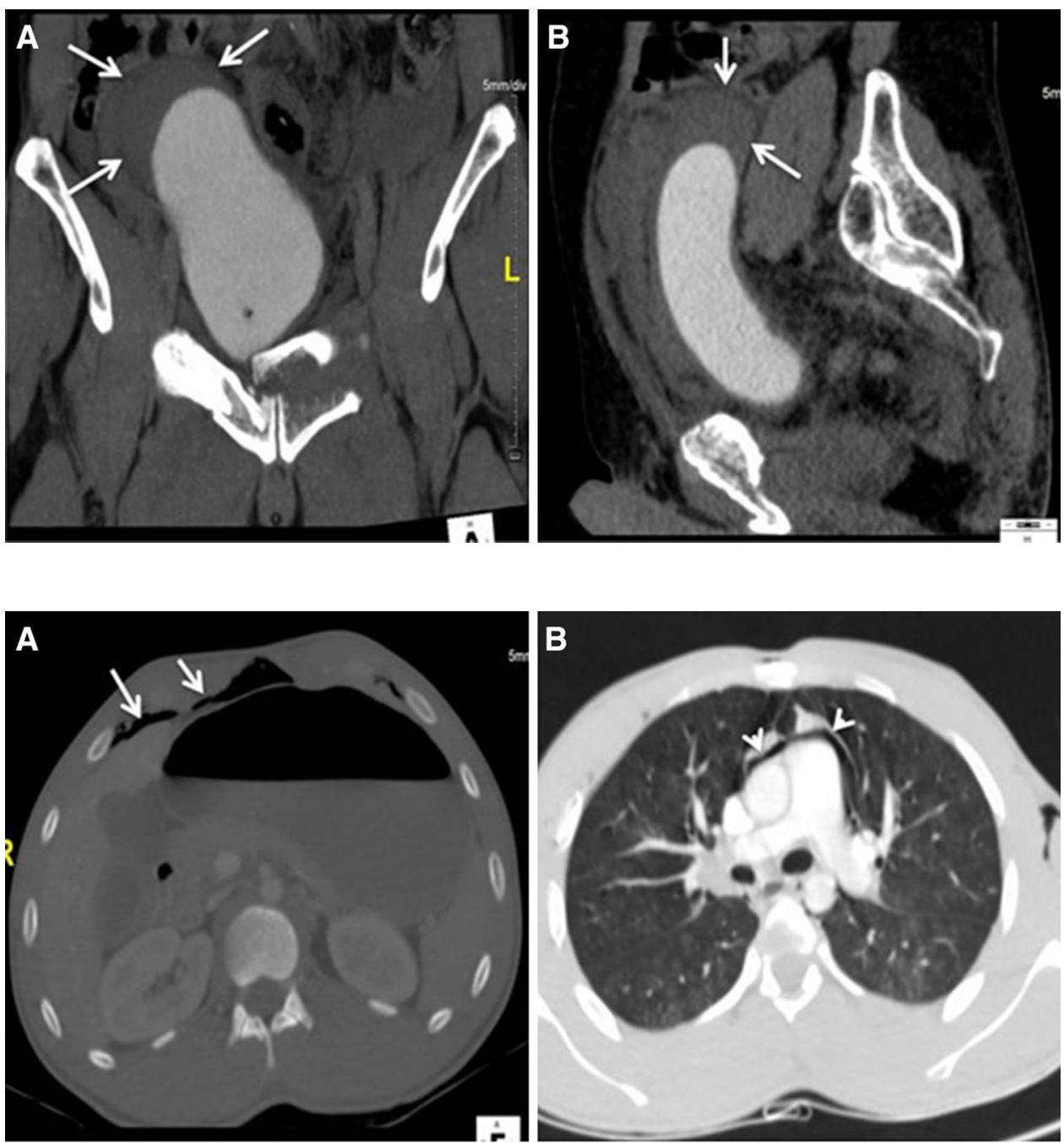

Fig. 15 Diaphragmatic injury. Pneumoperitoneum (arrows) is noted in axial (a) and coronal images (c, $\mathbf{d})$ which is extending into mediastinum leading to pneumomediastinum (arrowheads), as seen in (b) through a defect in the anterior aspect of the diaphragm (asterisk)
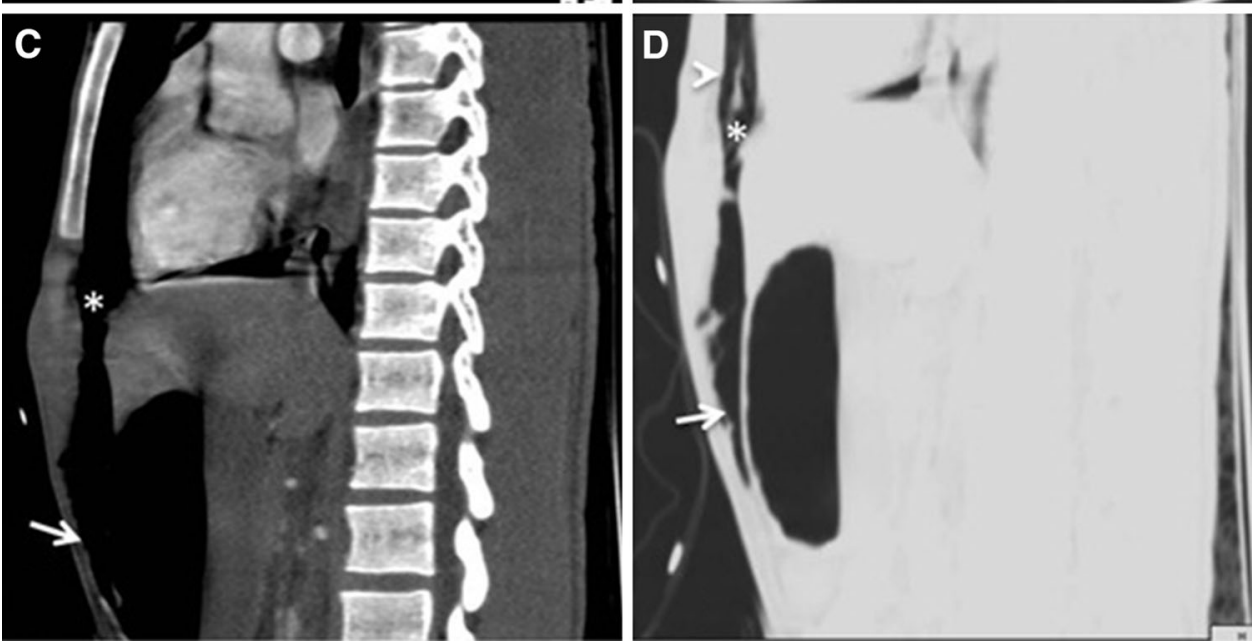

Various bladder injuries that can be depicted on CT Cystography include complete transmural tear which can either be intra or extraperitoneal. Distinction between these is of paramount importance because intraperitoneal ruptures are managed operatively whereas extraperitoneal ruptures can be conserved depending on need of surgery for other injuries. A recent (2010) study highlights this in which all the intraperitoneal ruptures were operated. At the same time, $36 \%$ of extraperitoneal ruptures were conserved [21•]. Another form is the combined intra and extraperitoneal rupture which is managed as an intraperitoneal rupture. 
Fig. 16 Bony injuries.

a Coronal MIP image of CT pelvis showing linear minimally displaced fracture of the left iliac bone parallel to the SI joint (arrows). b Axial MIP image showing Communited moderately displaced fractures of the superior and inferior pubic rami (arrowheads). c, d VRT images depicting the similar changes
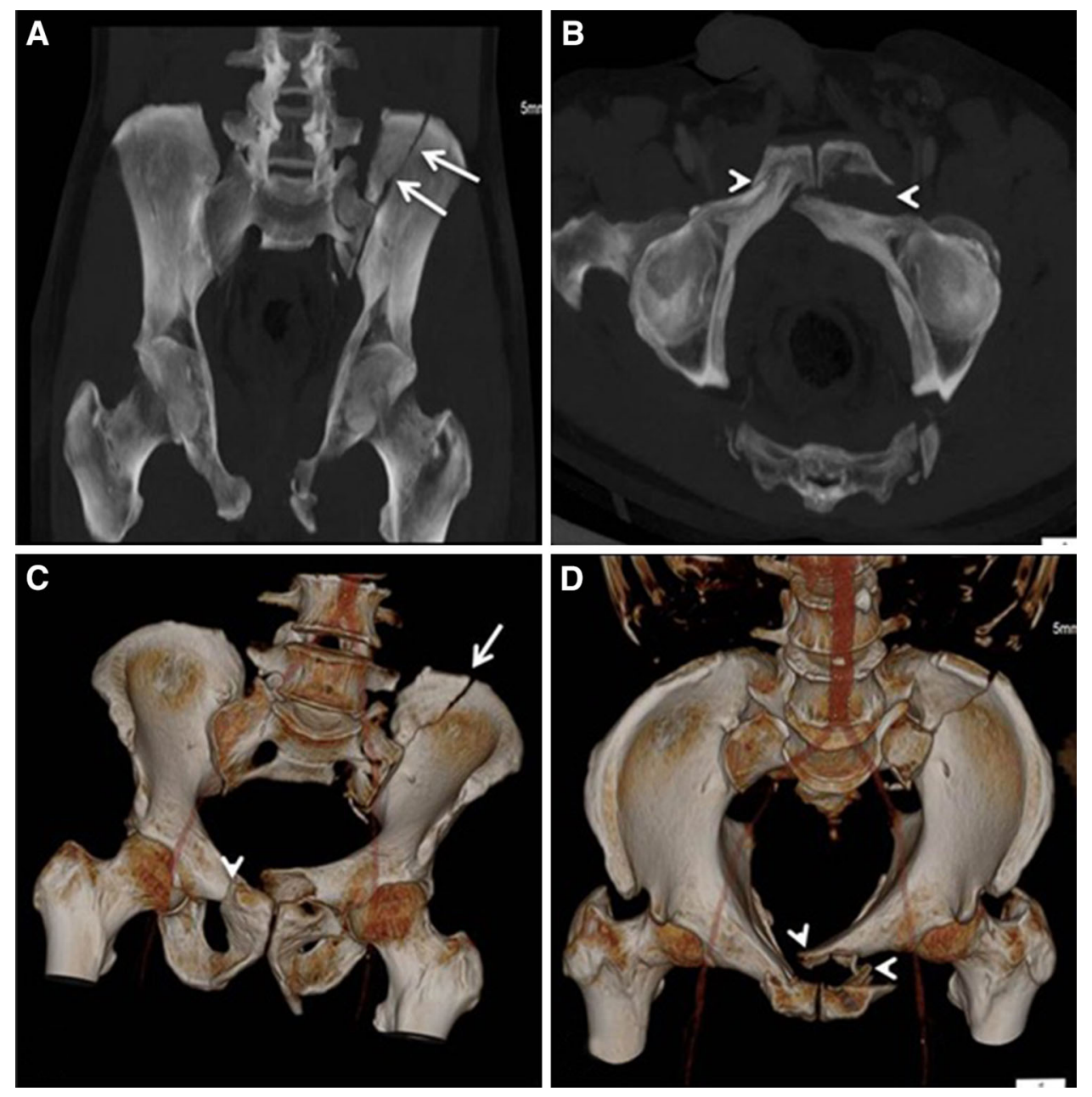

Fig. 17 Bony injuries: foreign body. Injury by fall from construction site. A metallic rod (arrows) was seen penetrating through the vertebral column into abdominal cavity.

However, no intra-abdominal major organ or vascular injuries were present and patient was operated for removal of the rod
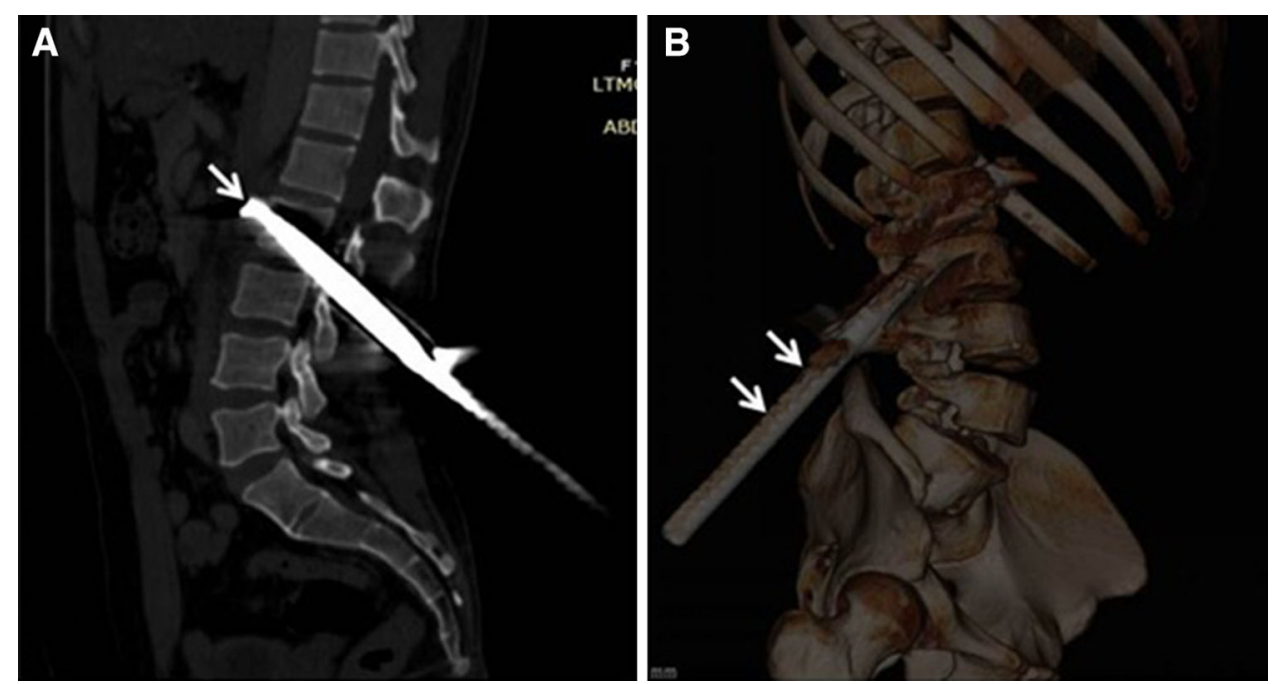


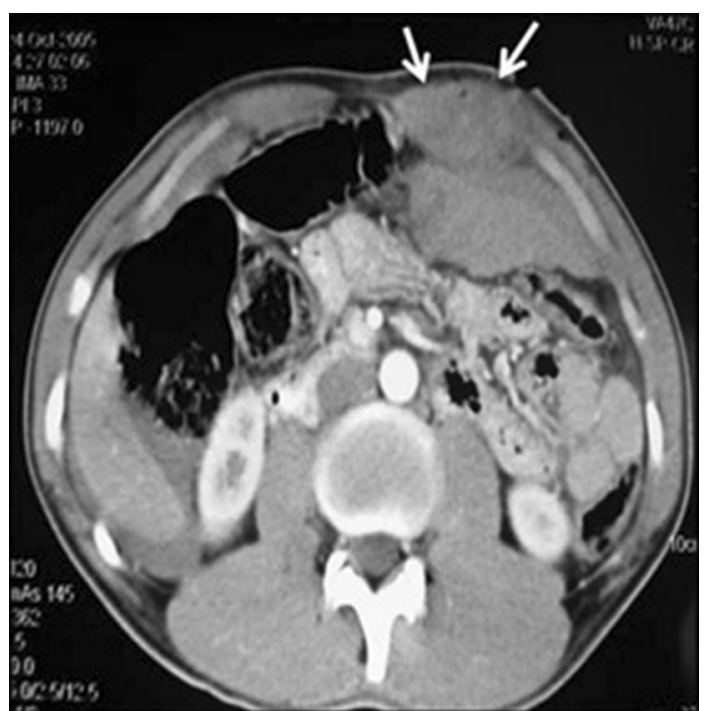

Fig. 18 Muscle injury. Rectus muscle hematoma. Axial CT images show a hyperdense hematoma in left rectus abdominis muscle (arrows), which appears bulky

Less common injuries are bladder contusion and interstitial injury which are generally managed conservatively (Figs. 12, 13, 14).

\section{Urethral Injury}

Urethra is injured in cases of pelvic trauma associated with pelvic fractures. Male urethral injuries are seen in $10 \%$ of the patients with pelvic fractures [22], whereas isolated urethral injury without pelvic fractures is not commonly noted [23]. A classification system devised by Goldmann is commonly used to classify the urethral injuries [24].

Clinical suspicion based on findings of blood at meatus, inability to void, elevated prostate gland dictates the imaging. RGU remains the gold standard for urethral trauma. On CT scan, urethral injury is mainly diagnosed/ suspected on the basis of indirect/adjuvant findings. Major findings seen on CT scan include distortion of fat plane around urogenital diaphragm, bulky ischiocavernous, or obturator internus muscles due to mural hematoma, nonappreciation of normal sharp prostatic contour etc. Extravasation of contrast on prior RGU or during active voiding by patient after CT Cystography can demonstrate urethral rupture above or below urogenital diaphragm by collection of extravasated contrast at respective locations. Presence of air foci in penis can also lead to diagnosis of urethral rupture if external injury is ruled out [23].

Thus, although not as a primary modality, CT does play a role as an adjuvant imaging modality in urethral trauma patients and may even be a primary diagnostic modality in cases of polytrauma patient where repeated shifting of patients may be ill advisable.

\section{Diaphragm}

Traumatic diaphragmatic hernias are far more common on left side, this can be related to the liver preventing the herniation on right side [25]. Discontinuity in the diaphragm is the most specific sign on CT scan. With MDCT, coronal and sagittal reformats make the diagnosis of diaphragmatic rupture easy and rapid (Fig. 15).

\section{Bony Injuries}

In the era of automation, high energy injuries have become commonplace, especially in vehicular trauma cases. Being a bedside investigation without need for special mobilization, X-rays are the backbone of fracture imaging. However, complete evaluation of pelvic ring and soft tissues is better with CT scan as compared to X-rays [26].

Most commonly used system is Young-Burgess classification for pelvic fractures which classifies fractures according to its mechanism of injury into antero-posterior compression, lateral compression, vertical shear, and a complex pattern [27]. Identification and classification of fractures is better with 3-D reconstructions in CT scan.

With the advent of newer technologies like real-time CT Fluoroscopy, CT has even been used in treatment of pelvic ring fractures in the form of CT fluoroscopy guided screw placements without subjecting the patient to excessively high radiation dose $[28 \bullet \bullet$.

Pelvic fractures are commonly associated with muscle injuries which are seen as bulky muscle which represent muscle hematomas. These are well seen on CT scan and although they may not be of immediate importance, these injuries may result in long-term effects such as prolapse (Figs. 16, 17, 18).

\section{Post-traumatic Complications}

After the acute settings of trauma, there are numerous complications in the survivors like bilioma, urinoma, arterio-venous fistulae, and abscesses [29, 30].

$\mathrm{CT}$ is the investigation of choice for follow-up cases. In addition to diagnostic value, CT can guide the therapeutic intervention in these conditions. 


\section{Conclusion}

CT scan is the diagnostic tool of choice in stable trauma patients. Multiphase evaluation, tailored protocols, and technical advances make it the most rapid, most sensitive as well as specific investigation in trauma patients. MDCT with MIP, MinIP, MPR, VRT, and SSD increases the diagnostic confidence of the emergency radiology consultant as well as help to understand the trauma surgeon. Serial evaluation in cases of ambiguous finding rather than operative approach in stable patients avoids unnecessary surgeries and its complications. CT is also equally important for chronic follow-up, diagnostic, and therapeutic interventions of chronic complications of trauma.

\section{Compliance with Ethics Guidelines}

Conflict of Interest Dr. Anagha R. Joshi is a section editor for Current Radiology Reports. Dr. Atish L. Komwad and Dr.Saurabh A. Joshi each declare no potential conflicts of interest.

Human and Animal Rights and Informed Consent This article does not contain any studies with human or animal subjects performed by any of the authors.

\section{References}

Papers of particular interest, published recently, have been highlighted as:

- Of importance;

•- Of major importance

1. - Soreide K. Epidemiology of major trauma. The British journal of surgery. 2009;96(7):697-8. Statistical analysis of trauma patients with epidemiological conclusions.

2. Haan JM, Bochicchio GV, Kramer N, Scalea TM. Nonoperative management of blunt splenic injury: a 5-year experience. J Trauma. 2005;58(3):492-8.

3. Sclafani SJ, Shaftan GW, Scalea TM, Patterson LA, Kohl L, Kantor A, et al. Nonoperative salvage of computed tomographydiagnosed splenic injuries: utilization of angiography for triage and embolization for hemostasis. J Trauma. 1995;39(5):818-25; discussion 26-7.

4. Federle MP, Goldberg HI, Kaiser JA, Moss AA, Jeffrey RB Jr, Mall JC. Evaluation of abdominal trauma by computed tomography. Radiology. 1981;138(3):637-44.

5. Cook DE, Walsh JW, Vick CW, Brewer WH. Upper abdominal trauma: pitfalls in CT diagnosis. Radiology. 1986;159(1):65-9.

6. Kane NM, Francis IR, Burney RE, Wheatley MJ, Ellis JH, Korobkin M. Traumatic pneumoperitoneum. Implications of computed tomography diagnosis. Investig Radiol. 1991;26(6):574-8.

7. Shanmuganathan K, Mirvis SE, Sover ER. Value of contrastenhanced $\mathrm{CT}$ in detecting active hemorrhage in patients with blunt abdominal or pelvic trauma. AJR Am J Roentgenol. 1993;161(1):65-9.

8. Mirvis SE, Gens DR, Shanmuganathan K. Rupture of the bowel after blunt abdominal trauma: diagnosis with CT. AJR Am J Roentgenol. 1992;159(6):1217-21.

9. • Moore EE, Shackford SR, Pachter HL, McAninch JW, Browner BD, Champion HR, et al. Organ injury scaling: spleen, liver, and kidney. J Trauma. 1989;29(12):1664-6. Most commonly followed system of grading of injuries.

10. Poletti PA, Mirvis SE, Shanmuganathan K, Killeen KL, Coldwell D. CT criteria for management of blunt liver trauma: correlation with angiographic and surgical findings. Radiology. 2000;216(2): 418-27.

11. Shanmuganathan K, Mirvis SE. CT scan evaluation of blunt hepatic trauma. Radiol Clin N Am. 1998;36(2):399-411.

12. - Patten RM, Spear RP, Vincent LM, Hesla RB, Jurkovich GJ. Traumatic laceration of the liver limited to the bare area: CT findings in 25 patients. AJR Am J Roentgenol. 1993;160(5): 1019-22. Bare area of liver laceration is different presentaion and important for noticing correctly.

13. Shanmuganathan K. Multidetector row CT imaging of blunt abdominal trauma. Semin Ultrasound CT MRI. 2004;25: 180-204.

14. Dowe MF, Shanmuganathan K, Mirvis SE, Steiner RC, Cooper C. CT findings of mesenteric injury after blunt trauma: implications for surgical intervention. AJR Am J Roentgenol. 1997; 168(2):425-8.

15. Rizzo MJ, Federle MP, Griffiths BG. Bowel and mesenteric injury following blunt abdominal trauma: evaluation with CT. Radiology. 1989;173(1):143-8.

16. Donohue JH, Federle MP, Griffiths BG, Trunkey DD. Computed tomography in the diagnosis of blunt intestinal and mesenteric injuries. J Trauma. 1987;27(1):11-7.

17. Scaglione M, Pinto F, Lassandro F, Romano L, Pinto A, Grassi R. Value of contrast-enhanced CT for managing mesenteric injuries after blunt trauma: review of five-year experience. Emerg Radiol. 2002;9(1):26-31.

18. McAninch J. Renal injuries. In: Gillenwater JYGJ, Howards SS, Duckett JW, editors. Adult and pediatric urology. 3rd ed. St Louis: Mosby; 1996. p. 539-53.

19. Vaccaro JP, Brody JM. CT cystography in the evaluation of major bladder trauma. Radiographics Rev Publ Radiol Soc N Am Inc. 2000;20(5):1373-81.

20. Mee SL, McAninch JW, Federle MP. Computerized tomography in bladder rupture: diagnostic limitations. J Urol. 1987;137(2): 207-9.

21. - Wirth GJ, Peter R, Poletti PA, Iselin CE. Advances in the management of blunt traumatic bladder rupture: experience with 36 cases. BJU Int. 2010;106(9):1344-9. Study highlighting the various methods of management of trauma to bladder.

22. Davidson AJ, et al. Radiologic evaluation of urinary tract trauma. In: Davidson AJ, Hartman DS, Choyke PL, Wagner BJ, editors. Davidson's radiology of the kidney and genitourinary tract. 3rd ed. Philadelphia: Saunders; 1999. p. 699-720.

23. Ali M, Safriel Y, Sclafani SJ, Schulze R. CT signs of urethral injury. Radiogr Rev Publ Radiol Soc N Am Inc. 2003;23(4): 951-63; discussion 63-6.

24. Goldman SM, Sandler CM, Corriere JN Jr, McGuire EJ. Blunt urethral trauma: a unified, anatomical mechanical classification. J Urol. 1997;157(1):85-9.

25. Heiberg E, Wolverson MK, Hurd RN, Jagannadharao B, Sundaram M. CT recognition of traumatic rupture of the diaphragm. AJR Am J Roentgenol. 1980;135(2):369-72.

26. Rommens PM, Vanderschot PM, Broos PL. Conventional radiography and CT examination of pelvic ring fractures. A comparative study of 90 patients. Der Unfallchirurg. 1992;95(8): 387-92.

27. Young JW, Burgess AR, Brumback RJ, Poka A. Pelvic fractures: value of plain radiography in early assessment and management. Radiology. 1986;160(2):445-51.

28. • Strobl FF, Haeussler SM, Paprottka PM, Hoffmann RT, Pieske $\mathrm{O}$, Reiser MF, et al. Technical and clinical outcome of percutaneous CT fluoroscopy-guided screw placement in unstable 
injuries of the posterior pelvic ring. Skelet Radiol. 2014;43(8): 1093-100. Novel use of CT Fluoroscopy in operative management.

29. Esensten M, Ralls PW, Colletti P, Halls J. Posttraumatic intrahepatic biloma: sonographic diagnosis. AJR Am J Roentgenol. 1983;140(2):303-5.
30. Knudson MM, Lim RC Jr, Oakes DD, Jeffrey RB Jr. Nonoperative management of blunt liver injuries in adults: the need for continued surveillance. J Trauma. 1990;30(12):1494-500. 